\title{
SINTESIS DAN KARAKTERISASI 1,4,7-TRIAZASIKLONONANA-1,4,7-ASAM TRIASETAT (NOTA) SEBAGAI LIGAN DALAM SENYAWA KOMPLEKS SEDIAAN RADIOTERAPI
}

\author{
Duyeh Setiawan $^{1 *}$, Iwan Hastiawan ${ }^{2}$ \\ ${ }^{1}$ Pusat Sains Dan Teknologi Nuklir Terapan - Badan Tenaga Nuklir Nasional \\ J1.Tamansari No. 71 Bandung 40132,Jawa Barat - Indonesia \\ ${ }^{2}$ Jurusan Kimia, Fakultas Matematika dan Ilmu Pengetahuan Alam, Universitas Padjadjaran \\ J1. Raya Bandung-Sumedang km. 21 Jatinangor, Sumedang 45363, Jawa Barat - Indonesia \\ *Alamat korespondensi: d_setiawan@Batan.go.id
}

\begin{abstract}
Abstrak: Perkembangan penelitian mengenai penggunaan ligan makrosiklik dalam beberapa tahun terakhir cukup pesat. Hal ini didasarkan pada sifatnya yang relatif stabil membentuk senyawa kompleks dengan ion logam valensi dua atau tiga. Di bidang kesehatan, ligan tersebut digunakan untuk sediaan radioterapi dalam bentuk senyawa kompleks radioisotop. Salah satu ligan makrosiklik yang berpotensi adalah 1,4,7triazasiklononana-1,4,7-asam triasetat (NOTA). Penelitian ini bertujuan memperoleh ligan makrosiklik NOTA untuk pembuatan senyawa kompleks radioisotop. Metode sintesis didasarkan pada reaksi antara 1,4,7triazasiklononana asam triklorida dengan larutan asam bromo asetat dalam litium hidroksida-etanol pada suhu 40-50 ${ }^{\circ} \mathrm{C}$ dan $\mathrm{pH} 10-11$ yang diaduk selama lima hari. Selanjutnya serbuk putih dikarakterisasi dengan spektrometer IR dan ${ }^{1} \mathrm{H}-\mathrm{NMR}$ serta kemurniannya dengan uji titik dekomposisi. Spektrum IR menunjukkan adanya vibrasi pada panjang gelombang 3434, 2905, 1602, 1437 dan $1160 \mathrm{~cm}^{-1}$. Spektrum ${ }^{1} \mathrm{H}-\mathrm{NMR}$ menunjukkan pergeseran kimia pada 3,22 dan 3,74 ppm. Hasil uji titik dekomposisi adalah $259^{\circ} \mathrm{C}$. Setelah membandingkannya dengan literatur menunjukkan bahwa produk yang dihasilkan diduga NOTA dengan rendemen $23,69 \%$.
\end{abstract}

Kata kunci : Ligan makrosiklik, NOTA (1,4,7-triazasiklononana-1,4,7-asam triasetat), radioterapi.

Abstract: The development of research on the use of macrocyclic ligands in recent years is quite rapid. The ligands form relatively stable complex compounds with divalent or trivalent metallic ions. In health sector they are used for radiotherapy, in the form of radioisotope complex compounds. One of the potential macro cyclic ligands is 1,4,7-triazacyclononane-1,4,7-triacetic acid (NOTA). This study aims to synthesize the macro cyclic ligand NOTA for the preparation of the complex compound of radioisotopes. The synthesis was based on the reaction between 1,4,7-triazacyclononane trichloride acid and bromo acetic acid in lithium hydroxide-ethanol solution at a temperature range of $40-50^{\circ} \mathrm{C}$ and a $\mathrm{pH}$ range of $10-11$, with stirring for five days. The reaction product, which was tested for its purity using the decomposition test, has a decomposition temperature of $259{ }^{\circ} \mathrm{C}$. The reaction product was characterized using IR and ${ }^{l} \mathrm{H}$-NMR spectrometry. The IR spectrum of the product showed vibration frequencies at 3434, 2905, 1602, 1437 and $1160 \mathrm{~cm}^{-1}$. Meanwhile, the $e^{1}$-NMR spectrum of the product showed chemical shifts at 3,223 and 3,745 ppm. By comparing the spectral data of the product with those given in the literature, it can be proposed that the product of the reaction was NOTA. The yield of the synthesis reaction was $23.69 \%$.

Keywords: macrocyclic ligands, NOTA(1,4,7-triazacyclononane-1,4,7-triacetaticacid), radiotherapy.

\section{PENDAHULUAN}

Jumlah penderita kanker di Indonesia kian meningkat. Data dari Kementerian Kesehatantahun 2012 menyebutkan, prevalensi kanker mencapai 4,3 banding 1.000 orang. Padahal data sebelumnya menyebutkan prevalensinya 1 banding 1.000 orang. Badan Kesehatan Dunia (BKD) dan Serikat Pengendalian Kanker Internasional (SPKI) memprediksi, akan terjadi peningkatan lonjakan penderita kanker sebesar 300 persen di seluruh dunia pada tahun 2030. Jumlah tersebut 70 persen berada di negara berkembang seperti Indonesia. Kenaikan prevalensi kanker di Indonesia menjadi masalah bagi pengobatan. Hal ini menuntut harus adanya berbagai jenis metode pengobatan untuk bisa menahan laju perkembangan penyakit tersebut secara signifikan dengan memanfaatkan teknologi nuklir menggunakan radioisotop.

Pemanfaatan teknologi radioisotop dapat menjadi solusi yang tepat sebagai jalan untuk mengatasi permasalahan tersebut. Hal ini didasarkan pada pemanfaatan pancaran sinar beta $(\beta)$ yang dimiliki oleh suatu radioisotop yang dapat berfungsi sebagai terapi radionuklida untuk menyembuhkan penyakit kanker tersebut. Sinar beta tersebut dapat menurunkan aktifitas biologis dari kanker, sehingga pertumbuhan sel kanker tersebut terhambat dan pada akhirnya sel tersebut mati.

Dalam aplikasinya radioisotop digunakan dalam bentuk senyawa kompleks radioaktif yang diikatkan 
dengan suatu ligan, yang dapat mengikat kuat logam radioaktif tersebut dan juga bersifat stabil. Ligan yang sering digunakan dalam pembentukan senyawa kompleks radioaktif tersebut adalah ligan makrosiklik.

Dalam beberapa tahun terakhir penelitian mengenai senyawa kompleks yang mengandung ligan makrosiklik yang mengandung gugus fungsi pada lengan sikliknya, cukup menarik perhatian terutama untuk radiofarmaka dan aplikasi biomedis (Valencia et al., 2001). Kompleks makro siklik ditandai dengan stabilitas termodinamika tinggi dan ketahanannya secara kinetik. Efek makrosiklik adalah istilah yang digunakan untuk menggambarkan pengamatan bahwa kompleks makrosiklik lebih stabil dari pada analog rantai terbuka mereka (Tei, 2001). Salah satu contohnya adalah tingkat kestabilan yang tinggi yang dibentuk dari makromolekul triaza (salah satu jenis makrosiklik) yang ditunjukkan dengan reaksi disosiasi yang sangat lambat saat diikatkan pada ion galium. Kekhasan harga konstanta disosiasinya adalah $10^{5}-10^{7}$ kali lebih lambat dibandingkan saat ion galium diikatkan dengan analog rantai terbuka (Velikyan \& Irina, 2005). Penjelasan mengenai penambahan gugus fungsi yang “diikatkan" kepada suatu kerangka makrosiklik dapat menyebabkan perubahan penting dalam kemampuan kompleksasi dari ligan dan juga dapat meningkatkan selektivitas ion logam tertentu dan stabilitas kompleks logam tergantung pada sifat dari lengan anting-anting tersebut (Valencia et al., 2001).

Ligan 1,4,7-triazasiklononana-1,4,7-asam triasetat (NOTA) adalah salah satu ligan makrosiklik (jenis poliaza) yang sering digunakan sebagai prekursor pembentukan senyawa kompleks dalam pengaplikasian pengobatan medis berbasis radiodiagnosa ataupun radioterapi. NOTA diteliti secara intensif sebagai ligan khelat makrosiklik multidentat sebagai pengkompleks yang luas terhadap ion metal bi- atau trivalen (Förster et al., 2011). NOTA khususnya digunakan sebagai pengompleks secara luas untuk ion metal bi- dan trivalen. Kompleks ini yang memiliki aplikasi medis sebagai agen pengkontras dan pengobatan kanker, diagnosis, terapi, dan lainnya (Anderegg et al., 2005).

\section{BAHAN DAN METODE}

Bahan kimia yang digunakan dalam penelitian diantaranya 1,4,7-triazasiklononana asam triklorida (Sigma-Aldrich), asam bromo asetat (Sigma-Aldrich), asam klorida $37 \%$, etanol $70 \%$, kalium bromida, dan litium hidroksida (Merck). Sedangkan peralatan yang digunakan adalah spektrometer Infra Red (IR), spektometer Nuclear Magnetic Resonance $(N M R)$,magneticstirer, termometer, neraca analitis dan peralatan gelas yang biasa digunakan dalam laboratorium.

\section{Metode Sintesis ligan1,4,7-triaza-siklononana-1,4,7- asam triasetat (NOTA)}

Sebanyak 5 mmol 1,4,7-triazasiklo-nonana asam triklorida dalam litium hidroksida-etanol direaksikan dengan asam bromo asetat dalam litium hidroksidaetanol sebanyak $15,39 \mathrm{mmol}$ dalam gelas kimia pada suhu $1-2^{\circ} \mathrm{C}$, sambil diaduk dengan menggunakan magnetic stirer. Kemudian suhu dinaikkan sampai 40$50^{\circ} \mathrm{C}$, dan $\mathrm{pH}$ larutan diatur sampai dicapai $\mathrm{pH} 10-11$. Pengadukan dilakukan selama 5 hari dengan kondisi reaksi dipertahankan (suhu $40-50^{\circ} \mathrm{C}$ dan $\mathrm{pH} 10-11$ ). Setelah 5 hari pengadukan dihentikan, $\mathrm{pH}$ larutan dijadikan netral denganpenambahan asam klorida $37 \%$. Selanjutnya, serbuk putih yang terbentuk dipisahkan dari larutannya dengan cara dekantasi. Serbuk putih yang didapat ditimbang dan disimpan dalam botol vial.

\section{Karakterisasi dengan menggunakan spektrometer IR dan spektrometer NMR, serta diuji kemurniannya}

Serbuk putih yang telah didapat digerus dengan menggunakan kalium bromida, lalu campuran diukur dengan alat spektrometer IR untuk memperoleh spektrumnya.

Selanjutnya sisa endapan putih dikarakterisasi dengan menggunakan spektrometer ${ }^{1} \mathrm{H}-\mathrm{NMR}$, dan kemurniannya diuji dengan uji titik dekomposisinya.

\section{HASIL DAN PEMBAHASAN \\ Sintesis NOTA}

Reaksi yang terjadi dalam sintesis NOTA adalah reaksi subtitusi nukleofilik bimolekular, hal ini disebabkan struktur senyawa R-X (asam bromo asetat) adalah alkil halida primer. Kondisi dari brom yang memiliki sifat elektronegatif lebih kecil dibandingkan dengan nitrogen (keelektronegatifan nitrogen $=4,03$; sedangkan brom $=2,96$ ), sehingga nitrogen lebih mudah untuk menggantikan posisi brom dalam ikatan, dan brom akan lepas (brom bersifat sebagaigugus lepas yang baik). Mekanisme reaksi pembentukan NOTA seperti ditunjukkan pada Gambar 1.

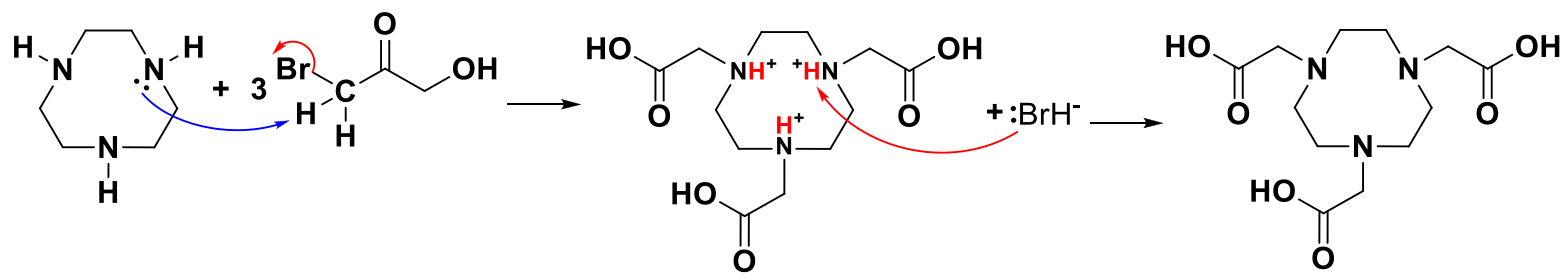

Gambar 1. Mekanisme reaksi sintesis NOTA 
Gambar 1 termasuk reaksi $\mathrm{S}_{\mathrm{N}} 2$, maka reaksi terjadi secara serempak. Dimana proses pergantian tiga hidrogen oleh 1,4,7- Triazasiklonona trihidroklorida (TACN) sebagai nukleofil berlangsung serentak bersama-sama, hal ini karena nukleofil yang menyerang hidrogen memiliki sifat yang sama. Secara stoikiometri (teoritis) jumlah NOTA yang didapat adalah 0,0764 g dan NOTA hasil percobaan adalah $0,0181 \mathrm{~g}$, sehingga diperoleh rendemen $23,69 \%$. Tidak tercapai banyaknya NOTA secara teoritis dikarenakan faktor-faktor sebagai berikut: (1) ketidak optimalan lingkungan reaksi akibat kondisi $\mathrm{pH}$ ataupun suhu yang sulit untuk dipantau selama pengadukan yang dilakukan selama 5 hari terus menerus, (2) proses dekantasi yaitu kemungkinan terbawanya endapan saat dipisahkan sehingga dapat membuat endapan tersebut jumlahnya berkurang.

\section{Karakterisasi NOTA}

Karakterisasi yang dilakukan yaitu dengan menggunakan spektrometer Infra Merah dan spektrometer ${ }^{1} \mathrm{H}-\mathrm{NMR}$ serta uji kemurnian dengan uji titik leleh.
Pengukuran serapan gelombang inframerah dalam suatu penentuan struktur bertujuan untuk mengetahui gugus-gugus fungsi yang terdapat pada suatu molekul. Identifikasi gugus fungsi tertentu ditunjukkan oleh serapan khas pada bilangan gelombang tertentu yang merupakan hasil transisi antara tingkat energi vibrasi (getaran) dari setiap interaksi atom-atom dalam suatu molekul, baik berupa bending (tekuk/lentur) ataupun stretching (regang). Dalam struktur NOTA terdapat beberapa jenis ikatan yang menyusunnya seperti yang ditunjukkan pada Gambar 2.<smiles>O=C(O)CN1CCN(CC(=O)O)CCN(CC(=O)O)CC1</smiles>

Gambar 2. Ikatan-ikatan yang terdapat dalam struktur NOTA

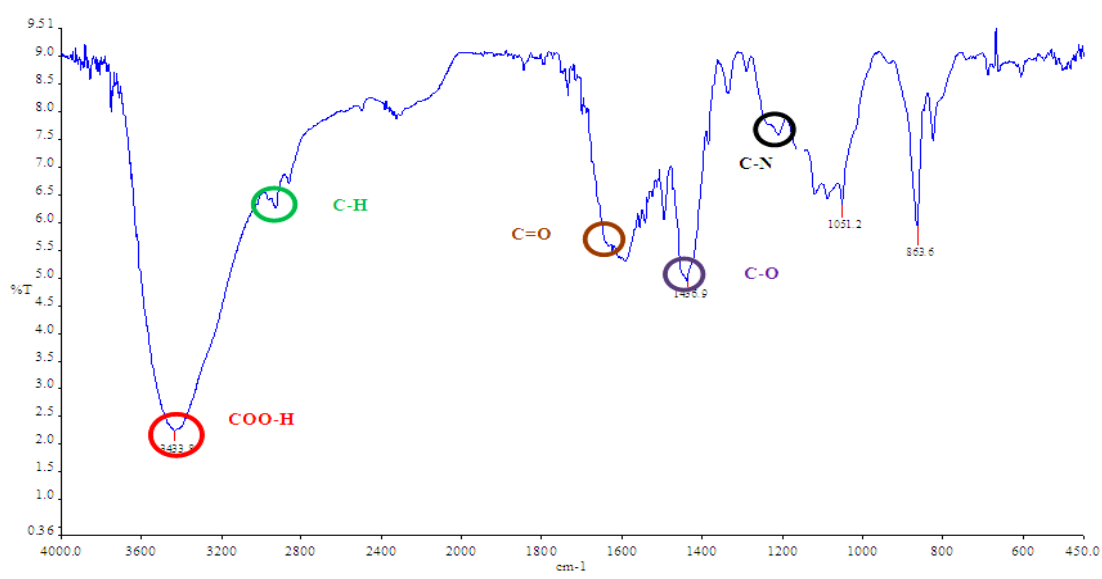

Gambar 3. Spektrum Infra Merah NOTA hasil sintesis

Tabel 1. Spektrum Infra Merah dari NOTA hasil sintesis dan pembanding.

\begin{tabular}{|c|c|c|c|c|}
\hline \multicolumn{2}{|c|}{ Bilangan gelombang $\left(\mathrm{cm}^{-1}\right)$} & \multirow{2}{*}{$\begin{array}{l}\text { Bentuk } \\
\text { puncak }\end{array}$} & \multirow[b]{2}{*}{ Intensitas } & \multirow{2}{*}{$\begin{array}{l}\text { Dugaan struktur/ } \\
\text { gugus fungsi }\end{array}$} \\
\hline Sintesis & Pembanding* & & & \\
\hline 3434 & 3408 & Lebar & Kuat & lentur O-H (hidroksida) \\
\hline 2905 & 2906 & Tajam & Sedang & regang $\mathrm{C}-\mathrm{H}\left(s p^{3}\right)$ \\
\hline 1602 & 1743 & Lebar & Kuat & rengang $\mathrm{C}=\mathrm{O}$ (karbonil) \\
\hline 1437 & 1389 & Lebar & Kuat & regang $\mathrm{C}-\mathrm{O}$ (karboksilat) \\
\hline 1160 & 1206 & Tajam & Sedang & regang $\mathrm{C}-\mathrm{N}$ (amina tersier) \\
\hline
\end{tabular}

Hasil spektrum Infra Merah yang didapat dari karakterisasi sampel hasil sintesis dapat dilihat pada Gambar 3.

Gambar 3 menunjukkan pola spektrum NOTA terdiri beberapa puncak yang muncul pada panjang gelombang yang berbeda-beda. Untuk menentukan bahwa hasil percobaan adalah NOTA, maka hasil spektrum Infra Merah tersebut dibandingkan dengan penelitian sebelumnya yang telah dilakukan oleh Pilip \& Bilewiz (2011). Adanya kemiripan puncak-puncak 
pada spektrum Infra Merah NOTA hasil sintesis dengan pembanding, hal ini menunjukkan bahwa terdapat kandungan gugus fungsi yang mirip seperti yang dirangkum pada Tabel 1.

Tabel 1 menunjukkan bahwa hasil sintesis dapat diduga adalah NOTA. Hal ini diperkuat dengan hasil karakterisasidengan menggunakan ${ }^{1} \mathrm{H}-\mathrm{NMR}$.
Dari hasil spektrum ${ }^{1} \mathrm{H}-\mathrm{NMR}$ NOTA hasil sintesis menunjukkan bahwa terdapat puncak adanya hidrogen pada gugus metil di daerah ikatan siklik (pergeseran kimia: 3,22 ppm) dan hidrogen pada gugus metil di lengan asetat (pergeseran kimia: 3,745 ppm). Spektrum ${ }^{1}$ H-NMR NOTA ditunjukkan seperti pada Gambar 4.

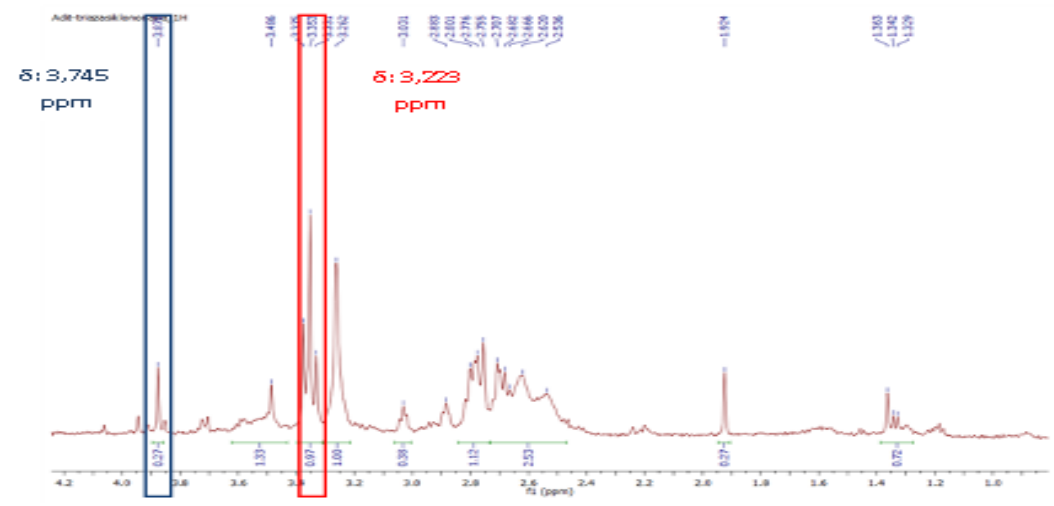

Gambar 4. Pergeseran kimia atom-atom hidrogen pada NOTA hasil sintesis

Adapun hasil penelitian Pilip \& Bilewicz (2011) memberikan data spektrum ${ }^{1} \mathrm{H}-\mathrm{NMR}$ terhadap gugusgugus yang terkandung dalam NOTA, yaitu: (1) pergeseran kimia $\left(\delta_{\mathrm{H}}\right) 3,43$ yang menunjukkan adanya atom-atom hidrogen pada gugus metil di ikatan siklik, (2) pergeseran kimia $\left(\delta_{\mathrm{H}}\right) 3,86$ yang menunjukkan adanya atom-atom hidrogen pada gugus metil di lengan asetat. Perbandingan antara nilai pergeseran kimia NOTA sintesis dengan pembanding dirangkum pada Tabel 2.
Tabel 2 menunjukkan nilai pergeseran kimia antara hasil sintesis dengan pembanding memiliki kemiripan, hal ini menunjukkan bahwa hasil yang diperoleh dapat diduga NOTA.

Pada pergeseran kimia $\left(\delta_{\mathrm{H}}\right) \quad 3,223$ ppm, menunjukkan bahwa multisiplitas yang terbentuk adalah triplet, hal ini disebabkan adanya dua atom hidrogen pada gugus metil tetangga disebelahnya, seperti ditunjukkan pada Gambar 5.

Tabel 2. Spektrum ${ }^{1} \mathrm{H}-\mathrm{NMR}$ dari NOTA hasil sintesis dan pembanding

\begin{tabular}{cccc}
\hline \multicolumn{2}{c}{ Pergeseran kimia (ppm) } & Multisiplitas & Dugaan \\
Sampel & Pembanding* & & \\
\hline 3,22 & 3,43 & Triplet & $-\mathrm{CH}_{2}$ - dalam ikatan siklik \\
3,74 & 3,86 & Singlet & $-\mathrm{CH}_{2}$ - sebagai lengan asetat \\
\hline$*$ (Pilip \& Bilewicz, 2011) & &
\end{tabular}<smiles>O=C(O)CN1CCN(CC(=O)O)CCN(CC(=O)O)CC1</smiles>

Gambar 5. Atom hidrogen dalam ikatan siklik

Hal ini menyebabkan multisiplitasnya menjadi triplet. Berbeda halnya dengan yang terjadi pada pergeseran kimia 3,75 ppm, dimana multisiplitas yang terbentuk berupa singlet, hal ini disebabkan tidak<smiles>O=C(O)CN1CCN(CC(=O)O)CCN(CC(=O)O)CC1</smiles>

Gambar 6. Atom hidrogen dalam lengan asetat

adanya atom hidrogen di gugus metil tetangga sebelahnya, seperti yang ditunjukkan pada Gambar 6 .

Sebenarnya, dalam strukutur NOTA terdapat 3 lingkungan hidrogen yaitu atom hidrogen yang 
terdapat pada gugus hidroksida di lengan asetat. Hal tersebut dapat dilihat pada Gambar 7.

Akan tetapi karena adanya efek resonansi yang terjadi pada karbon yang mengikat oksigen pada gugus karbonil dengan karbon yang sama yang mengikat gugus hidroksida, hal ini mengakibatkan pada proses karakterisasi dengan menggunakan spektrometer ${ }^{1} \mathrm{H}-\mathrm{NMR}$ lingkungan hidrogen tersebut sulit untuk dibaca. Reaksi resonansi yang terjadi dapat dilihat pada Gambar 8.<smiles>O=C(O)CN1CCN(CC(=O)O)CCN(CC(=O)O)CC1</smiles>

Gambar 7. Atom hidrogen yang terdapat pada gugus hidroksida<smiles>O=C(O)CN1CCN(CC(=O)O)CCN(CC(=O)O)CC1</smiles>

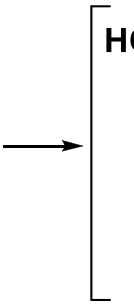<smiles>O=C(O)CN1CCN(CC(=O)O)CCN(CC(=O)O)CC1</smiles>

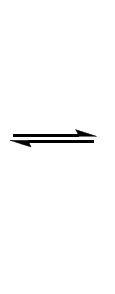<smiles>O=C([O-])CN1CCN(CC(=O)O)CCN(CC(=O)O)CC1</smiles>

Gambar 8. Reaksi resonansi yang terjadi di lengan asetat

Perbedaan nilai panjang gelombang dari gugus fungsi yang sama pada spektrum Infra merah antara sampel dan pembanding, dan juga perbedaan nilai pergeseran kimia antara sampel dan pembanding pada spektrum ${ }^{1} \mathrm{H}-\mathrm{NMR}$ yang tidak signifikan dapat dikarenakan banyak faktor, antara lain: (1) pengaruh dari pengotor. Dimana adanya pengotor dalam sampel dapat memberikan pergeseran pada nilai dari suatu panjang gelombang, (2) alat yang digunakan dalam proses karakterisasi berbeda, dimana hal tersebut mempengaruhi perbedaan spektrum IR yang dihasilkan.

Pada spektrum ${ }^{1} \mathrm{H}$-NMRterdapat puncak-puncak di daerah 2,4-2,75 dan daerah 3,13 ppm, dimana hal tersebut menunjukkan adanya pengotor dalam sampel tersebut yang diduga etanol. Hal ini dapat dilihat pada Gambar 9.

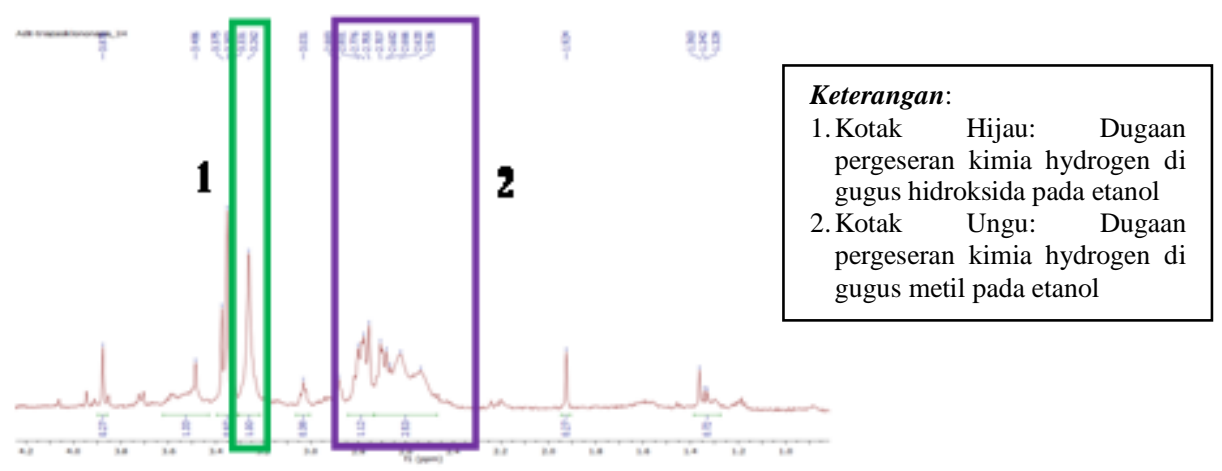

Gambar 9. Pergeseran kimia atom hidrogen pengotor pada sampel NOTA

Adanya pengotor etanol dalam sampel kemungkinan disebabkan etanol yang digunakan sebagai pelarut belum menguap sempurna pada proses pengeringan, dimana sebelumnya etanol tersebut digunakan sebagi pelarut dalam sintesis NOTA. Untuk menguji kemurniannya dilakukan uji titik dekomposisi. Dari uji tersebut didapat titik dekomposisi dari serbuk putih yang didapat adalah $259^{\circ} \mathrm{C}$ yang nilainya masuk dalam daerah titik dekomposisi NOTA pada literatur (Grob $\&$ Elias, 1996) yaitu pada daerah $250-260^{\circ} \mathrm{C}$, sehingga dapat diduga serbuk putih yang disintesis adalah NOTA.

\section{KESIMPULAN}

1. Reaksi antara 1,4,7-triazasiklononana asam triklorida dengan asam bromo asetat menghasilkan serbuk putih 0,0181 gram dengan rendemen $23,69 \%$ yang diduga adalah NOTA.

2. Hasil spektrum IR serbuk putih yang disintesis menunjukkan adanya vibrasi pada panjang gelombang 3434, 2905, 1602, 1437 dan $1160 \mathrm{~cm}^{-1}$. Pada spektrum ${ }^{1} \mathrm{H}-\mathrm{NMR}$ menunjukkan pergeseran kimia pada 3,223 ppm dan 3,745 ppm. Pada uji 
kemurnian dengan uji titik dekomposisi didapat titik dekomposisi serbuk putih yang telah disintesis adalah $259^{\circ} \mathrm{C}$. Setelah membandingkannya dengan literatur menunjukkan bahwa produk yang dihasilkan dapat diduga sebagai NOTA (1,4,7-triazasiklononana-1,4,7asam triasetat), yang memiliki struktur kimia seperti dibawah ini:<smiles>O=C(O)CN1CCN(CC(=O)O)CCN(CC(=O)O)CC1</smiles>

Gambar 10. Struktur dari NOTA

\section{UCAPAN TERIMA KASIH}

Ucapan terima kasih disampaikan kepada Adhitya Fikrie Z.R., Jurusan Kimia, Fakultas Matematika dan Ilmu Pengetahuan Alam, Universitas Padjadjaran Bandung.

\section{DAFTAR PUSTAKA}

Anderegg, G., Arnauld-Neu, F., Delgado, R., Felcman, J., \& Popov, K. (2005). Cricital evaluation of stability constants of metal complexes of complexones for biomedical and environmental applications. Pure App. Chem.,77, 1445-1495.
Förster, C., Schubert, M., Pietzsch, H.J., \& Steinbach, J. (2011).Maleimido-functionalized NOTA derivatives as bifunctional chelators for sitespecific radiolabeling. Molecules, 16, 5228-5240.

Grob, S., \& Elias, H. (1996). Kinetics and mechanism of complex formation : the reaction of nickel (II) with 1,4,7-triazacyclononane- $N, N^{\prime}, N^{\prime \prime}$-triacetic acid. Inorganic Chimica Acta, 251, 347-354.

Pilip, A.M. \& Bilewicz, A. (2011). Scandium-47 Complexes as precursors for therapeutic radiopharmaceuticals. Journal of Inorganic Biochemsitry, 105, 313-320.

Tei, L. (2001). Studied on Functionalised Macrocyclic Ligands. University of Nothingham, Nothingham.

Valencia, L., Adams, H., Bastida, R., Fenton, D. E., Macias, A., Mahia, J., \& Spey, S.E. (2001). The synthesis of three novel pendant armed macrocyclic ligands. The X-ray crystal structure of a cadmium complex derived from the first oxaazamacrocycle bearing two alkylated aromatic amine functions. Polyhedron, 20, 30913099.

Velikyan, \& Irina (2005). Synthesis, Characterisation and application of ${ }^{68} \mathrm{Ga}$-labelled macromolecules. Digital comprehensive summaries of Uppsala Dissertations from the Faculty of Science and Technology, Acta Universitatis Upsaliensis, Uppsala, 73, 68, ISBN 91-554-6295-2. 